\title{
WACANA GRAFITI BAK TRUK DALAM BAHASA INDONESIA, BAHASA DAERAH, DAN BAHASA ASING
}

\author{
Sudaryanto $^{1}$, Kresna Sugiarto ${ }^{2}$, Mita Restiana ${ }^{3}$ \\ Fakultas Keguruan dan Ilmu Pendidikan, Universitas Ahmad Dahlan \\ ${ }^{1}$ sudaryanto@pbsi.uad.ac.id, ${ }^{2}$ kresna1700003058@webmail.uad.ac.id \\ 3mita1700003045@webmail.uad.ac.id
}

\begin{abstract}
Abstrak
Wacana grafiti bak truk merupakan contoh nyata dari konsep permainan bahasa (language game) di kehidupan sehari-hari. Wacana tersebut mudah diakses oleh siapa pun, termasuk para pengguna jalan. Tujuan penelitian ini adalah mendeskripsikan wujud, tujuan, dan genre wacana grafiti bak truk dalam bahasa Indonesia, bahasa daerah, dan bahasa asing. Penelitian ini menggunakan pendekatan kualitatif dengan jenis penelitian deskriptif. Instrumen yang digunakan dalam penelitian ini ada dua, yaitu instrumen pengumpulan data dan analisis data. Instrumen pengumpulan data pada penelitian ini berupa tabel pengumpul data, sedangkan instrumen analisis data berupa tabel panduan analisis data dan tabel analisis data. Data pada penelitian ini adalah teks grafiti bak truk yang diambil dari sejumlah laman (website) di internet. Hasil penelitian ini adalah sebagai berikut. Pertama, wujud wacana grafiti bak truk dalam bahasa Indonesia, bahasa Jawa, dan bahasa Inggris. Kedua, tujuan wacana grafiti bak truk memiliki fungsi ekspresif, fungsi fatis, fungsi kognitif, dan fungsi komunikatif. Ketiga, genre wacana grafiti bak truk berupa doa, pantun kilat, idiom, dan judul lagu.
\end{abstract}

Kata Kunci: wacana grafiti, bak truk, bahasa Indonesia, bahasa daerah, bahasa asing

\begin{abstract}
Truck graffiti discourse is a real example of the concept of language games in everyday life. The discourse is easily accessible to anyone, including road users. The purpose of this study is to describe the form, purpose, and genre of truck-tailed graffiti discourse in Indonesian, regional languages, and foreign languages. This study uses a qualitative approach with a type of descriptive research. There are two instruments used in this study, namely the instrument of data collection and data analysis. The instrument of data collection in this study is a data collection table, while the data analysis instrument is a data analysis guide table and data analysis table. The data in this study are truck-like graffiti text taken from several pages (websites) on the internet. The results of this study are as follows. First, the form of truck-tailed graffiti in Indonesian, Javanese, and English. Second, the purpose of truck-like graffiti discourse has the expressive function, phatic function, cognitive function, and communicative function. Third, the genre of truck graffiti discourse is in the form of prayer, flash rhymes, idioms, and song titles.
\end{abstract}

Keywords: graffiti discourse, truck, Indonesian language, regional language, foreign language

\section{PENDAHULUAN}

Konsep permainan bahasa (language game) bersifat nyata dalam kehidupan sehari-hari. Artinya, konsep tersebut dapat dilihat, didengar, dan diraba secara riil oleh siapa saja. Salah satu wujud dari konsep permainan bahasa yang bersifat nyata dalam kehidupan sehari-hari adalah wacana grafiti bak truk. Wacana tersebut dapat diakses oleh siapa pun, termasuk para pengguna jalan. Bagi masyarakat Indonesia yang sering 
mengendarai sepeda motor atau mobil, serta menumpang kendaraan umum, wacana grafiti bak truk selalu menjadi hal yang menarik dan unik untuk diperhatikan, terutama dari segi permainan bahasa.

Hal terakhir itulah yang melatarbelakangi peneliti untuk meneliti lebih lanjut perihal wacana grafiti bak truk. Ditinjau dari definisinya, wacana memiliki arti sebanyak lima buah. Kelima buah arti itu adalah (1) komunikasi verbal, (2) keseluruhan tutur yang merupakan suatu kesatuan, (3) satuan bahasa terlengkap yang direalisasikan dalam bentuk karangan atau laporan utuh, seperti novel, buku, artikel, pidato, atau khotbah, (4) kemampuan atau prosedur berpikir secara sistematis; kemampuan atau proses memberikan pertimbangan berdasarkan akal sehat, dan (5) pertukaran ide secara verbal (Kridalaksana, 2011: 259; Sudaryanto, 2017: 111).

Di antara kelima arti di atas, tampaknya yang sesuai dengan grafiti bak truk ialah arti nomor 3, satuan bahasa terlengkap yang direalisasikan dalam bentuk karangan atau laporan utuh, seperti novel, buku, artikel, pidato, atau khotbah. Dengan demikian, grafiti bak truk dapat dinyatakan sebagai satuan bahasa terlengkap yang direalisasikan dalam bentuk karangan atau laporan utuh. Menurut Kamus Besar Bahasa Indonesia Daring (Badan Pengembangan dan Pembinaan Bahasa, 2016), grafiti adalah coretan dalam berbagai bentuk (kata, simbol, dan sebagainya) dan warna yang terdapat pada tembok atau dinding properti umum.

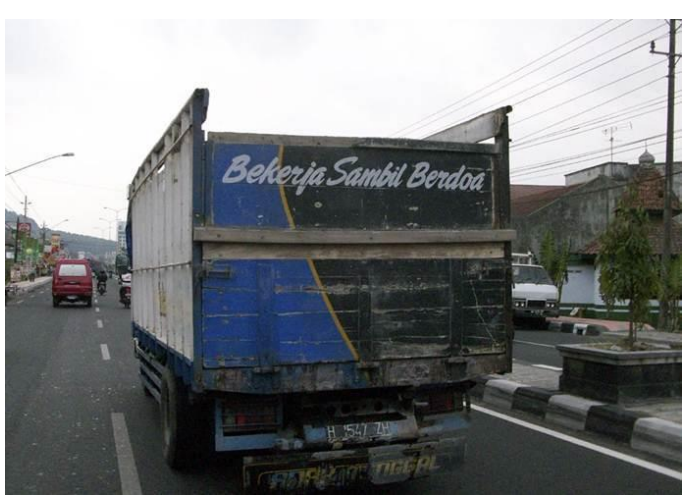

Gambar 1 Contoh Grafiti Bak Truk

Terkait itu, sejumlah pakar telah menghasilkan kajian yang bersinggungan dengan wacana grafiti bak truk, seperti Wicandra (2009), Hoogervorst (2009), Meliana (2014), Junawaroh (2015), dan Ismail (2016). Wicandra lebih berfokus ke arah representasi perempuan pada lukisan bak truk (Wicandra, 2009). Hoogervorst lebih berkonsentrasi ke arah impresi masyarakat urban di Kota Surabaya (Hoogervorst, 2009). Sementara itu, Meliana, Junawaroh, dan Ismail lebih menitikberatkan ke arah tindak tutur pada grafiti bak truk, baik dalam bahasa Indonesia maupun bahasa Jawa (Ismail, 2016; Junawaroh, 2015; Meliana, 2014).

Kelima kajian di atas sesungguhnya masih memiliki kekurangan berupa belum dianalisisnya wujud, tujuan, dan genre grafiti bak truk dalam bahasa Indonesia, bahasa daerah, dan bahasa asing. Untuk itulah, kajian ini akan mendeskripsikan wujud, tujuan, dan genre grafiti bak truk dalam bahasa Indonesia, bahasa daerah, dan bahasa asing. Tulisan ini akan berurutan membahas metode penelitian, hasil dan pembahasan, simpulan, dan daftar pustaka. Dalam bagian hasil dan pembahasan akan dilengkapi gambargambar grafiti bak truk yang relevan dengan uraiannya. 


\section{METODE PENELITIAN}

Penelitian ini menggunakan pendekatan kualitatif dengan jenis penelitian deskriptif. Jenis penelitian deskriptif sesuai dengan parodi dari Nida bahwa "describe facts, all the facts and nothing but the facts". Jenis penelitian deskriptif sangat tepat diterapkan dalam kajian linguistik, baik linguistik mikro (microlinguistics) maupun linguistik makro (macrolinguistics), termasuk juga linguistik interdisipliner. Kajian mengenai wacana grafiti bak truk dalam bahasa Indonesia, bahasa daerah, dan bahasa asing ini tergolong ke dalam jenis penelitian deskriptif.

Subjek penelitian ini adalah grafiti bak truk yang terpublikasikan di sejumlah laman (website) di internet. Sementara itu, objek penelitian ini adalah wujud, tujuan, dan genre grafiti bak truk dalam bahasa Indonesia, bahasa daerah, dan bahasa asing. Metode pengumpulan data yang digunakan dalam penelitian ini adalah metode analisis konten dengan teknik baca dan catat (Krippendorf, 2004: 21). Instrumen yang digunakan dalam penelitian ini ada dua, yaitu instrumen pengumpulan data dan analisis data. Instrumen pengumpulan data pada penelitian ini berupa tabel pengumpul data, sedangkan instrumen analisis data berupa tabel panduan analisis data dan tabel analisis data.

Desain yang digunakan dalam penelitian ini merupakan estimasi terhadap gejala yang terdapat pada data. Pola wujud, tujuan, dan genre wacana grafiti bak truk dalam bahasa Indonesia, bahasa daerah, dan bahasa asing yang akan dideskripsikan menyangkut beberapa gejala, maka parameter yang digunakan juga meliputi beberapa parameter sesuai dengan gejala yang dideskripsikan. Jika diskemakan dapat digambarkan sebagai berikut.
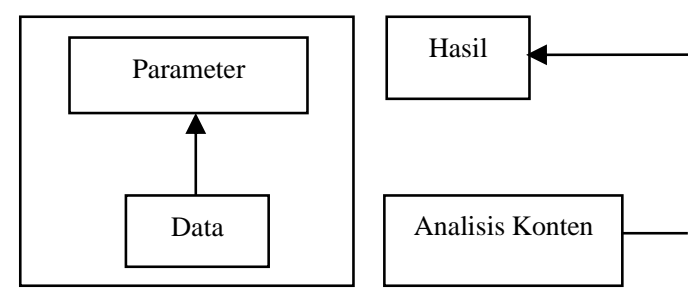

Gambar 2 Skema Desain Penelitian

Pengumpulan data dilakukan dengan teknik membaca dan mencatat secara cermat grafiti bak truk dalam bahasa Indonesia, bahasa daerah, dan bahasa asing yang dijadikan contoh melalui kartu data. Wacana grafiti bak truk dalam bahasa Indonesia, bahasa daerah, dan bahasa asing akan dipilahpilah berdasarkan tujuan penelitian ini, yaitu (1) mendeskripsikan wujud wacana grafiti bak truk dalam bahasa Indonesia, bahasa daerah, dan bahasa asing, (2) mendeskripsikan tujuan wacana grafiti bak truk dalam bahasa Indonesia, bahasa daerah, dan bahasa asing, dan (3) mendeskripsikan genre wacana grafiti bak truk dalam bahasa Indonesia, bahasa daerah, dan bahasa asing.

\section{HASIL DAN PEMBAHASAN}

Bagian ini menyajikan hasil penelitian dan pembahasan mengenai wacana grafiti bak truk dalam bahasa Indonesia, bahasa daerah, dan bahasa asing. Secara berurutan, diuraikan mengenai wujud, tujuan, dan genre wacana grafiti bak truk dalam bahasa Indonesia, bahasa daerah, dan bahasa asing. Uraian tersebut disertakan pula gambar-gambar atau foto-foto grafiti bak truk dalam bahasa Indonesia, bahasa daerah, dan bahasa asing yang relevan.

\section{Wujud Wacana Grafiti Bak Truk}

Wacana grafiti bak truk memiliki tiga wujud, yaitu dalam bahasa Indonesia, bahasa daerah, dan bahasa asing. Bahasa daerah yang dimaksudkan ialah bahasa Jawa. Menurut Sudaryanto, bahasa Jawa 
adalah bahasa yang dituturkan oleh suku Jawa. Sementara itu, bahasa asing yang dimaksudkan ialah bahasa Inggris (Sudaryanto, 2017: 53). Menurut Sudaryanto, bahasa Inggris adalah nama bahasa bangsa Inggris (Sudaryanto, 2017: 50). Gambar 3, 4, dan 5 merupakan contoh wacana grafiti bak truk dalam bahasa Indonesia, bahasa Jawa, dan bahasa Inggris. Dari 39 data grafiti bak truk, grafiti bak truk dalam bahasa Indonesia lebih dominan daripada grafiti bak truk dalam bahasa Jawa dan bahasa Inggris.

\section{Wujud Wacana Grafiti Bak Truk dalam Bahasa Indonesia}

Gambar 3 merupakan contoh grafiti bak truk dalam bahasa Indonesia. Di dalam grafiti itu tertera tulisan yang berbunyi, "Jangan malu, apa pun pekerjaanmu. Malulah ketika dirimu tidak bekerja." Frasa tidak bekerja ditulis dengan huruf kapital yang memiliki pesan penting kepada para pembaca grafiti itu agar tidak usah malu dengan pekerjaan yang dilakukan, seperti bekerja sebagai sopir. Alih-alih begitu, malulah ketika kita, termasuk para pembaca grafiti itu, justru tidak bekerja apa pun.

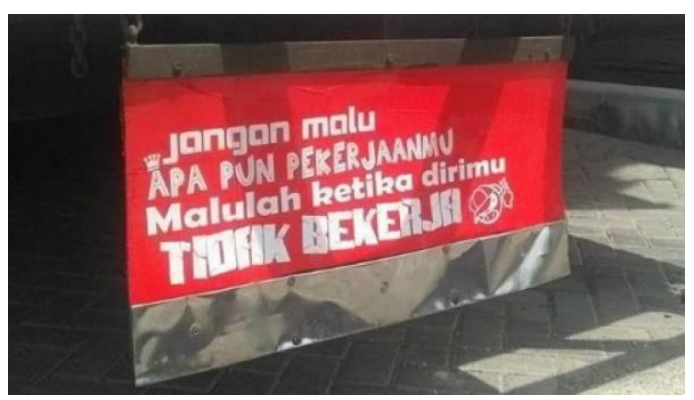

Gambar 3 Grafiti Bak Truk dalam Bahasa Indonesia

\section{Wacana Grafiti Bak Truk dalam Bahasa Jawa}

Gambar 4 merupakan contoh grafiti bak truk dalam bahasa Jawa. Di dalam grafiti itu tertera tulisan berbunyi, "Gara-Gara SMS Bojoku Minggat". Kata Bojo berasal dari bahasa Jawa yang artinya 'suami atau istri'. Ditambah kata ganti $k u$ menjadi Bojoku berarti 'suamiku' atau 'istriku'. Kata minggat juga berasal dari bahasa Jawa yang artinya 'pergi dari rumah'. Biasanya, sopir truk itu lakilaki, maka dalam konteks tulisan "GaraGara SMS Bojoku Minggat", berarti yang pergi dari rumah si sopir adalah istrinya.

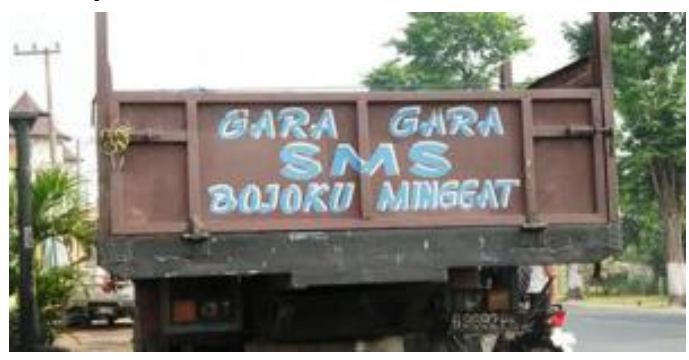

Gambar 4 Grafiti Bak Truk dalam Bahasa Jawa

\section{Wujud Wacana Grafiti Bak Truk dalam Bahasa Inggris}

Gambar 5 merupakan contoh grafiti bak truk dalam bahasa Inggris. Di dalam grafiti itu tertera tulisan berbunyi, "Lelahmu buat Masa Depanmu. Tetap Semangat Sayang. Semoga penuh berkah. Aamiin. Love you." Frasa Love you berasal dari bahasa Inggris yang artinya 'mencintai kamu'. Tulisan ini semacam pesan dari istri sopir kepada suaminya yang sedang bekerja sebagai sopir truk agar tetap semangat dalam bekerja demi masa depan keluarganya.

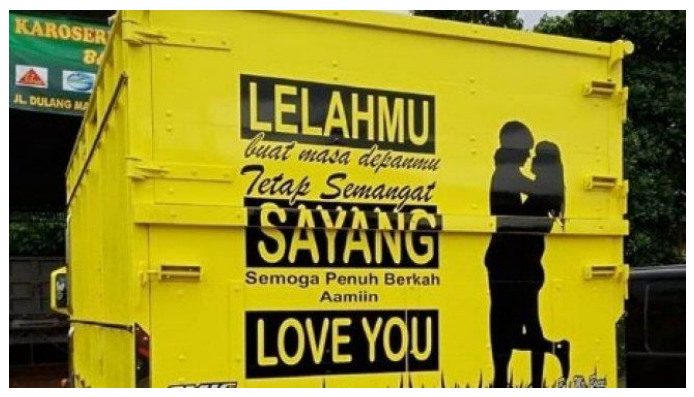

Gambar 5 Grafiti Bak Truk dalam Bahasa Inggris 


\section{Tujuan Wacana Grafiti Bak Truk}

Tujuan wacana grafiti bak truk terbagi ke dalam empat fungsi, yaitu (1) fungsi ekspresif, (2) fungsi fatis, (3) fungsi kognitif, dan (4) fungsi komunikatif. Menurut Kridalaksana, fungsi ekspresif adalah penggunaan bahasa untuk menampakkan hal-ihwal yang bersangkutan dengan pribadi pembicara, fungsi fatis adalah penggunaan bahasa untuk mengadakan atau memelihara kontak antara pembicara dan pendengar, fungsi kognitif adalah penggunaan bahasa untuk penalaran akal, dan fungsi komunikatif adalah penggunaan bahasa untuk penyampaian informasi antara pembicara/ penulis dan pendengar/ pembaca (Kridalaksana, 2011: 67-68).

\section{Fungsi Ekspresif}

Fungsi ekspresif terlihat pada Gambar 6 dan 7. Gambar 6 grafiti bak truk bertuliskan, "Neng Lilis Gadis Sumedang, Kutunggu Kedatanganmu". Neng itu nama panggilan bagi gadis yang belum menikah di daerah Jawa Barat. Grafiti itu juga dilengkapi gambar seorang gadis berambut hitam sebahu, berkaus pendek putih, dan memakai rok pendek merah. Dengan adanya tulisan dan gambar itu, tersampaikan pesan bahwa si sopir truk sedang menunggu kedatangan gadis impiannya bernama Neng Lilis yang merupakan gadis asal Sumedang, Jawa Barat.

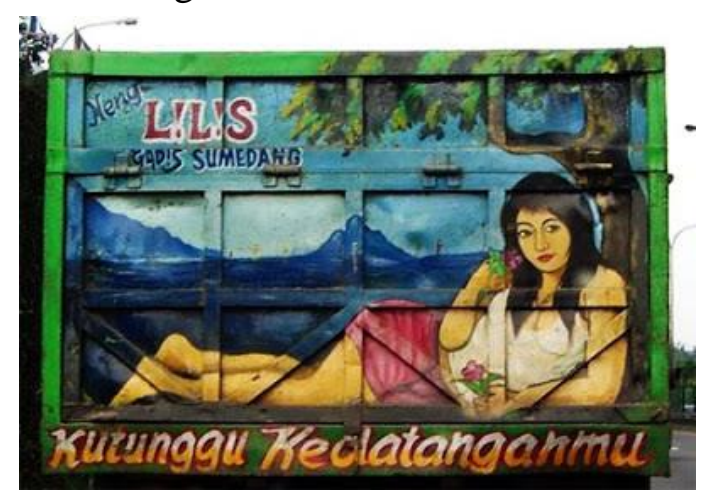

Gambar 6 Grafiti "Neng Lilis Gadis Sumedang, Kutunggu Kedatanganmu"

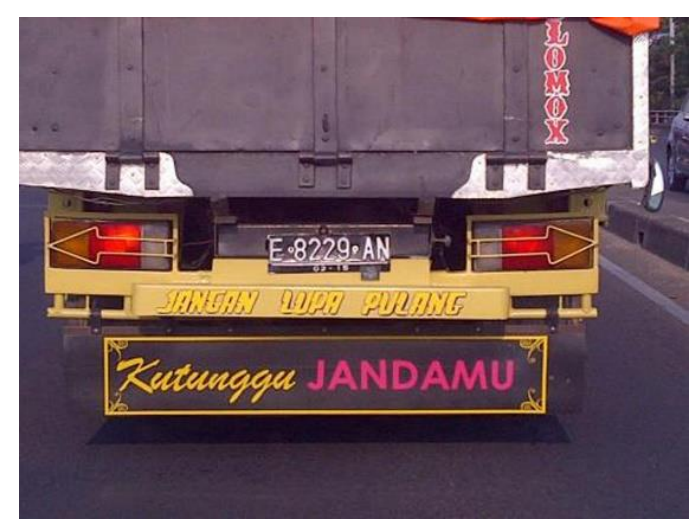

Gambar 7 Grafiti "Kutunggu Jandamu”

Gambar 7 grafiti bak truk bertuliskan, "Kutunggu Jandamu". Lewat grafiti itu tersampaikan pesan bahwa si sopir truk sedang menunggu status janda seseorang. Memang tidak tertulis nama seseorang yang ditunggu status jandanya seperti Gambar 6 . Namun demikian, grafiti bak truk Gambar 7 menegaskan bahwa si sopir sedang menunjukkan urusan pribadinya kepada orang lain, terlepas dari benartidaknya status perkawinan si sopir. Selain tulisan "Kutunggu Jandamu", ada pula tulisan "Jangan Lupa Pulang" yang bermaksud agar si sopir tidak lupa pulang ke rumahnya.

\section{Fungsi Fatis}

Fungsi fatis terlihat pada Gambar 8 dan 9. Gambar 8 grafiti bak truk bertuliskan, "Sambil nyetir kita dzikir". Penggunaan kata kita menegaskan bahwa si sopir seolah-olah mengajak para pembaca grafiti untuk ikut berzikir sambil menyetir. Pada tulisan itu dijumpai bunyi rima /ir/ pada kata (men-)nyetir dan berzikir. Menurut KBBI Daring (Badan Pengembangan dan Pembinaan Bahasa, 2016), zikir memiliki tiga makna, yaitu (1) puji-pujian kepada Allah yang diucapkan berulang-ulang, (2) doa atau puji-pujian berlagu (dilakukan pada perayaan Maulid Nabi), dan (3) perbuatan mengucapkan zikir. Tulisan grafiti bak truk "Sambil nyetir 
kita dzikir" itu lebih tepatnya mengarah ke makna nomor 3, yaitu perbuatan mengucapkan zikir.

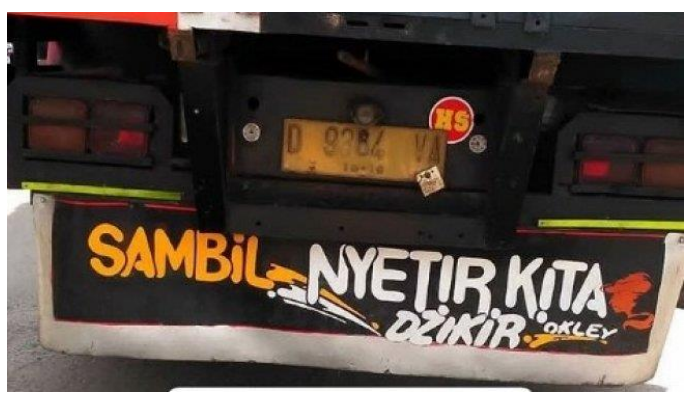

Gambar 8 Grafiti "Sambil Nyetir Kita Dzikir"

Sementara itu, Gambar 9 grafiti bak truk bertuliskan, "Putus Cinta Soal Biasa, Putus Rem Mati Kita". Lewat grafiti itu, si sopir hendak menyampaikan pesan atau nasihat kepada para pembaca grafiti bahwa putus cinta itu soal biasa, tapi putus rem itu berbahaya bahkan bisa menyebabkan kematian bagi si sopir atau semua pengguna kendaraan. Penggunaan kata kita menunjukkan bahwa si sopir seolah-olah mengajak pembaca grafiti untuk menganggap putus cinta itu hal biasa, sedangkan putus rem itu hal berbahaya bagi dirinya sendiri dan orang lain yang juga samasama pengguna kendaraan di jalan raya.

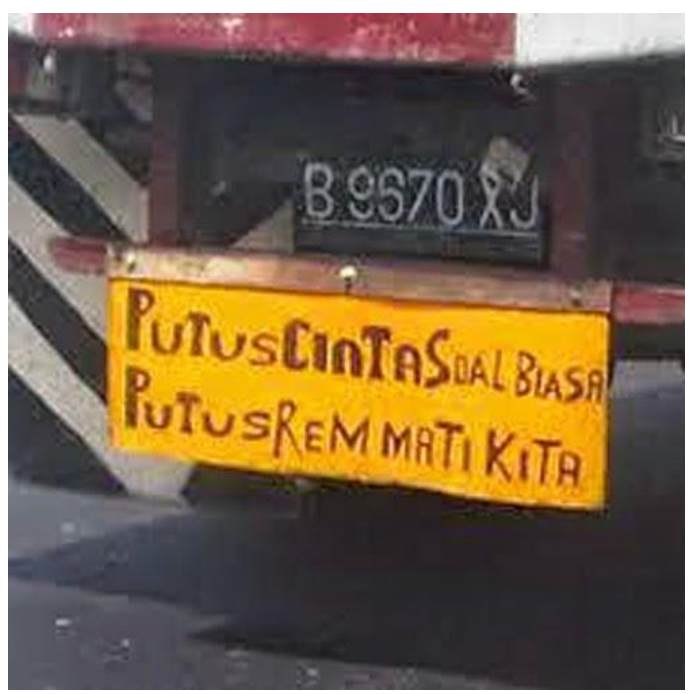

Gambar 9 Grafiti "Putus Cinta Soal Biasa, Putus Rem Mati Kita"

\section{Fungsi Kognitif}

Fungsi kognitif terlihat pada Gambar 10 dan 11. Gambar 10 grafiti bak truk bertuliskan, "Ngebut adalah ibadah. Semakin ngebut, semakin dekat dengan Tuhan." Lewat grafiti itu, si sopir bermaksud menyampaikan pesan bahwa cara dia mengendarai truk itu dengan mengebut (biasanya disebut ngebut), dan mengebut itu bagian dari ibadah, layaknya salat. Dengan demikian, si sopir truk hendak menyampaikan pesan bahwa mengebut itu bagian dari kerjanya sehari-hari, dan para pengguna jalan lainnya harap maklum. Selain itu, mengebut sangat berisiko terhadap terjadinya kecelakaan di jalan sehingga kalimat "semakin ngebut semakin dekat dengan Tuhan" itu bermakna mengebut dapat mengakibatkan kematian.

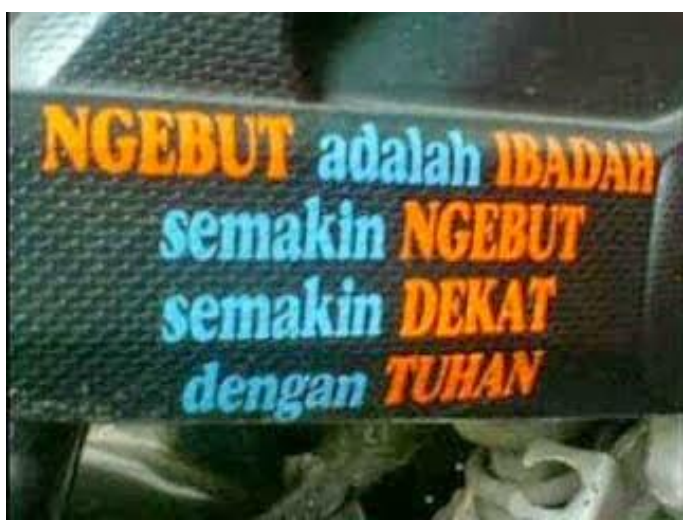

Gambar 10 Grafiti "Ngebut adalah ibadah, semakin ngebut semakin dekat dengan Tuhan"

Gambar 11 grafiti bak truk bertuliskan, "Asal Abang kuat nanjak lewat aje". Kata Abang itu bermakna (1) 'kakak laki-laki; saudara laki-laki yang lebih tua', (2) 'kata sapaan kepada orang lakilaki yang lebih tua atau tidak dikenal', dan (3) 'kata sapaan kepada penjual sayur, penjual ikan, pengemudi becak, dan sebagainya' (Badan Pengembangan dan Pembinaan Bahasa, 2016). Sementara itu, kata Aje itu berasal dari bahasa Betawi atau Melayu Betawi yang bermakna 'saja'. Selain tulisan "Asal Abang kuat nanjak lewat aje", grafiti itu 
dilengkapi dengan gambar perempuan yang berparas cantik, berbaju putih dan merah jambu. Melalui grafiti itu, si sopir hendak menyampaikan pesan bahwa jika pengendara lain ingin menyalip truknya, maka dipersilakan, asalkan pengendara lain itu kuat dalam posisi menanjak.

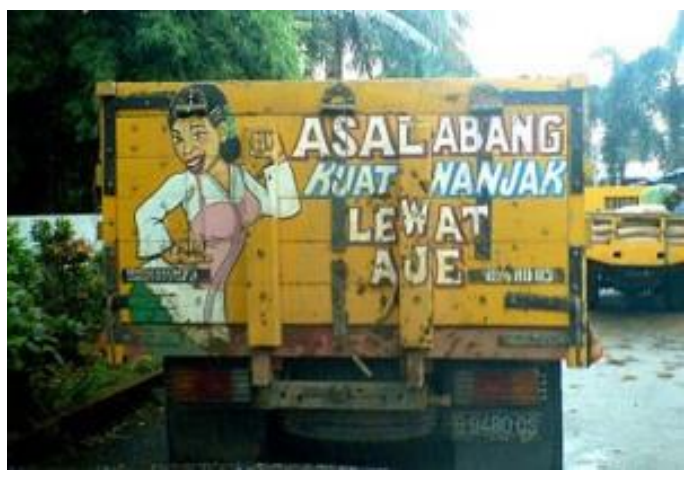

Gambar 11 Grafiti "Asal Abang kuat nanjak lewat aje"

\section{Fungsi Komunikatif}

Fungsi komunikatif terlihat pada Gambar 12. Gambar 12 grafiti bak truk bertuliskan, "Cintamu tak semurni solarku." Lewat grafiti itu, si sopir hendak menyampaikan pesan bahwa cinta pembaca grafiti itu tidak semurni solar yang digunakan oleh si sopir dalam mengendarai truknya. Solar itu sendiri merupakan bahan bakar minyak untuk mesin diesel, lebih kental daripada minyak tanah. Dengan demikian, jika si sopir mengatakan, "cintamu tak semurni solarku", artinya solar yang ia gunakan untuk mengendarai truknya itu benarbenar asli, bukan oplosan. Atau, bisa juga arti dari tulisan "cintamu tak semurni solarku" adalah cinta pembaca grafiti yang setengah-setengah atau kurang tulus, dan berbeda dengan solar yang digunakan oleh si sopir dalam mengendarai truknya.

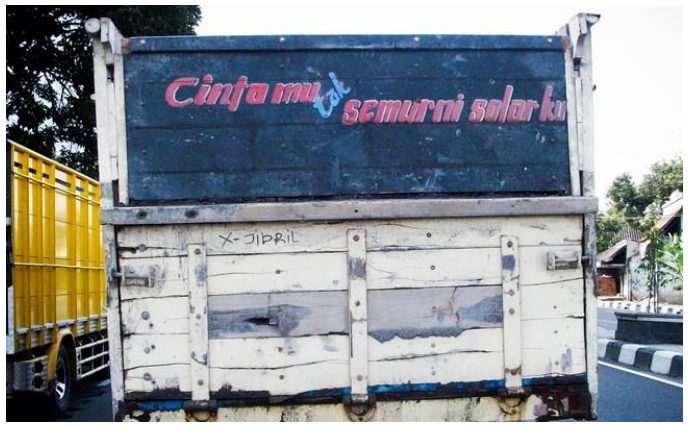

Gambar 12 Grafiti "Cintamu tak semurni solarku"

\section{Genre Wacana Grafiti Bak Truk}

Genre wacana grafiti bak truk terbagi menjadi empat jenis, yaitu doa, pantun kilat, idiom, dan judul lagu. Doa, menurut KBBI Daring (Badan Pengembangan dan Pembinaan Bahasa, 2016), berarti 'permohonan (harapan, permintaan, pujian) kepada Tuhan'. Pantun kilat, menurut KBBI Daring (Badan Pengembangan dan Pembinaan Bahasa, 2016) sama dengan karmina. Kemudian idiom, menurut KBBI Daring (Badan Pengembangan dan Pembinaan Bahasa, 2016), berarti (1) 'konstruksi yang maknanya tidak sama dengan gabungan makna unsurnya, misalnya kambing hitam dalam kalimat dalam peristiwa itu hansip menjadi kambing hitam, padahal mereka tidak tahu apaapa' dan (2) 'bahasa dan dialek yang khas menandai suatu bangsa, suku, kelompok, dan lain-lain'. Selanjutnya, judul lagu merupakan bagian dari sebuah karya lagu.

\section{Genre Doa}

Doa merupakan salah satu genre wacana grafiti bak truk. Umumnya, doa itu tertulis dalam bahasa Indonesia. Sebagai contoh, lihatlah Gambar 13 berupa grafiti bak truk yang berupa doa, " $Y a$ Allah, ampunilah dosa ${ }^{2} k u$, selama aku mengambil kesenangan di atas penderitaan orang lain." Atau, ada juga Gambar 14 berupa grafiti bak truk yang 
berupa doa, "Ya Allah, lindungilah aku dari godaan cabe-cabean, para mantan, wanita $^{2}$ penghibur, tante ${ }^{2}$ girang, jand ${ }^{2}$ muda, istri orang. Amiiiin!" Melalui dua buah grafiti itu, diperoleh pesan bahwa si sopir truk selalu berdoa kepada Allah Swt. agar dosa-dosa dirinya mohon diampuni dan dirinya dilindungi dari segala macam godaan, seperti cabecabean, para mantan (pacar/kekasih), wanita penghibur, tante girang, janda muda, dan istri orang lain.

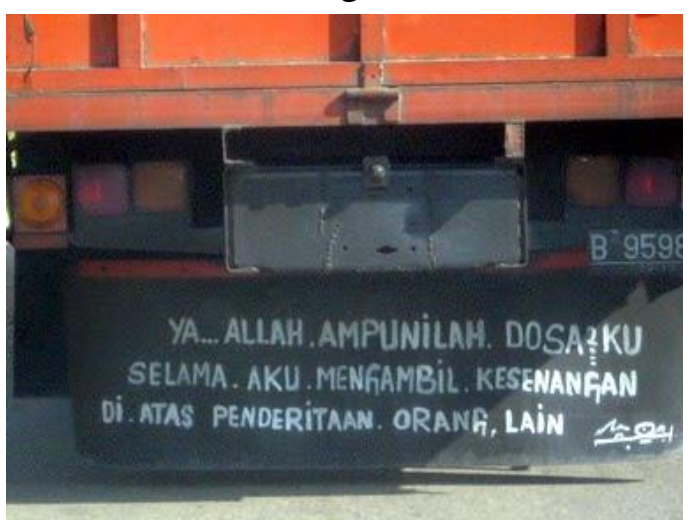

Gambar 13 Grafiti Bak Truk Genre Doa

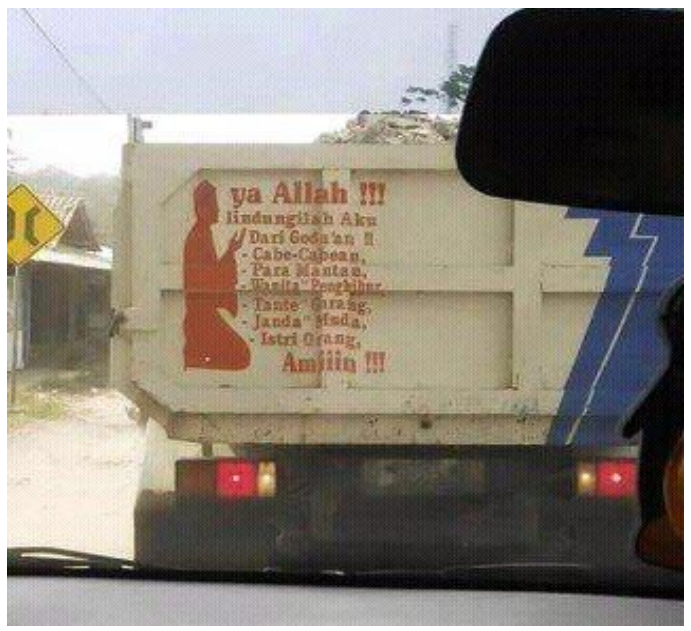

Gambar 14 Grafiti Bak Truk Genre Doa

\section{Genre Pantun Kilat}

Pantun kilat merupakan salah satu genre wacana grafiti bak truk. Pantun kilat biasanya ditulis dalam bahasa Indonesia dan bahasa Jawa. Sebagai contoh, grafiti bak truk (Gambar 15) tertulis "Cintamu bersemi/ saat dompetku berisi". Pada tulisan itu ada bunyi rima /i/ pada kata bersemi dan berisi. Pesan di balik pantun kilat itu bahwa saat si sopir memiliki pendapatan atau gaji yang lumayan, maka cinta seseorang (mungkin istri atau kekasih hatinya) bersemi. Dan sebaliknya, jika pendapatan si sopir berkurang, maka cinta seseorang tadi menghilang.

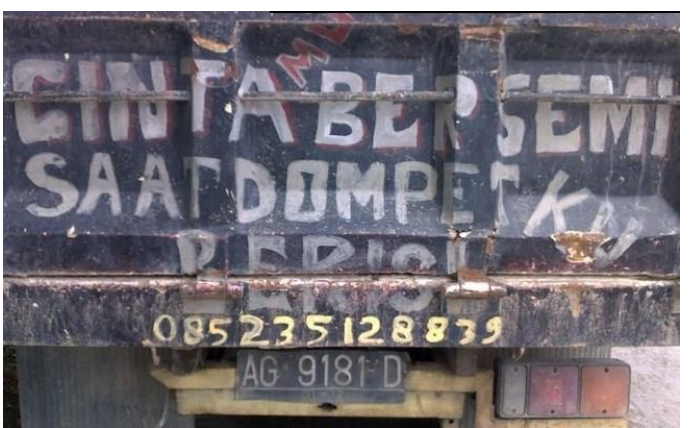

Gambar 15 Grafiti Bak Truk Genre Pantun Kilat Bahasa Indonesia

Lain pantun kilat bahasa Indonesia, lain pula pantun kilat bahasa Jawa. Gambar 16 grafiti bak truk genre pantun kilat berbahasa Jawa tertulis, "Ojo ngomong sayang, nek durung sembahyang", artinya 'Jangan ngomong sayang, jika belum sembahyang'. Pada tulisan itu ada bunyi rima / $/ \mathrm{y}$ pada kata sayang dan sembahyang. Selain tulisan, ada pula gambar dua orang perempuan berusia muda yang berjilbab dan berparas cantik. Pesan di balik pantun kilat itu bahwa dua perempuan itu seolah berkata kepada kekasihnya (barangkali si sopir truk) agar salat dulu, baru kemudian bertemu dengan dirinya.

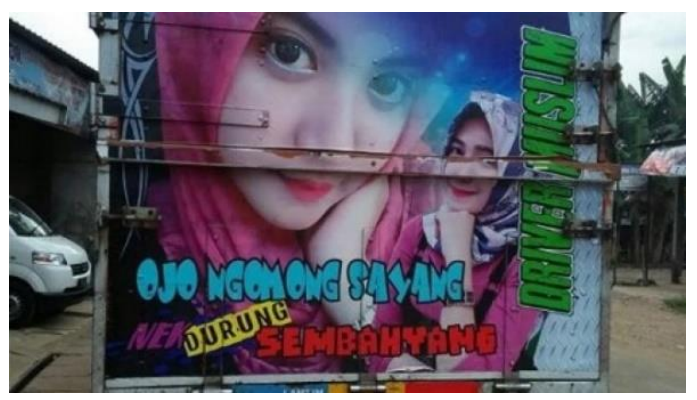

Gambar 16 Grafiti Bak Truk Genre Pantun Kilat Bahasa Jawa 


\section{Genre Idiom}

Idiom merupakan salah satu genre grafiti bak truk. Idiom yang ditemukan umumnya ditulis dalam bahasa Indonesia. Misalnya, grafiti bak truk (Gambar 17) bertuliskan idiom "Cintamu tak seberat muatanku". Tulisan itu jika dikaitkan dengan aktivitas sopir mengangkut muatan barang dari satu ke kota lain; dari satu daerah ke daerah lain tentu dapat dipahami secara baik. Pesan di balik grafiti itu menegaskan bahwa cinta seseorang (mungkin kekasih si sopir) itu tidak seberat muatan yang dibawanya dengan truknya. Muatan di truknya itu jauh lebih penting daripada rasa cinta seseorang yang mungkin kurang tulus, kurang menerima, atau kurang menghargai diri si sopir selama ini.

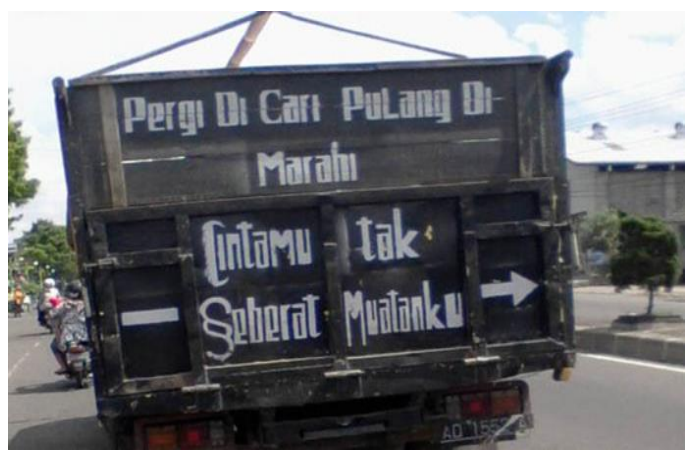

Gambar 17 Grafiti Bak Truk Genre Idiom Bahasa Indonesia

Selain itu, ada pula grafiti bak truk (Gambar 18) yang bertuliskan idiom "Surga di telapak kaki ibu". Idiom ini sangat populer di kalangan orang Indonesia, terutama saat menasihati anak agar dirinya patuh atau taat kepada ibunya. Idiom "surga di telapak kaki ibu" itu sebenarnya bermakna agar semua anak patuh kepada ibunya, sekalipun anak itu tadi sudah berkeluarga. Namun demikian, grafiti bak truk itu melakukan penyimpangan makna idiom tadi. Di dalam grafiti itu ada gambar sosok anak yang mencium telapak kaki ibunya dengan maksud ingin memperoleh surga.

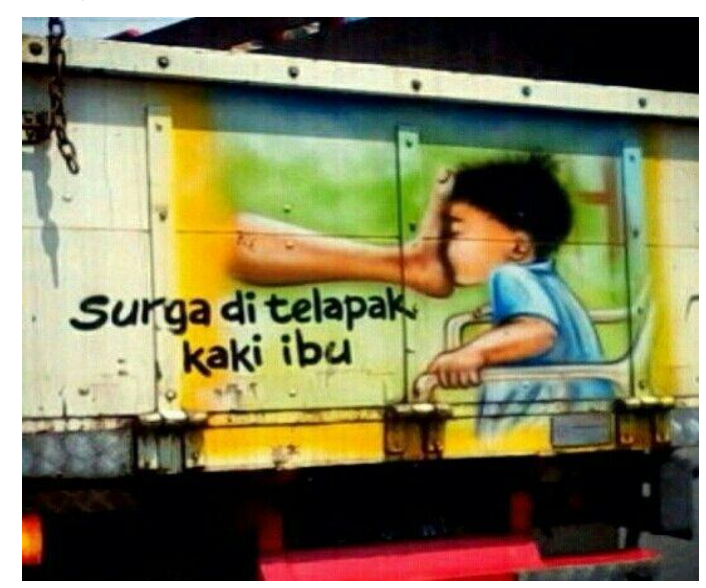

Gambar 18 Grafiti Bak Truk Genre Idiom "Surga di Telapak Kaki Ibu"

\section{Genre Judul Lagu}

Judul lagu merupakan salah satu genre wacana grafiti bak truk. Salah satu judul lagu yang digunakan sebagai grafiti bak truk adalah "Begadang" karya Rhoma Irama (Gambar 19, Rhoma Irama merupakan penyanyi Indonesia yang terkenal dengan julukan "Raja Dangdut". Ia banyak menghasilkan lagulagu terkenal di masyarakat Indonesia, seperti "Istri Salehah", "Lari Pagi", "Mirasantika", dan "Judi". Melalui grafiti bak truk bertuliskan salah judul lagu Rhoma Irama itu, si sopir hendak menyampaikan pesan kepada pembaca grafiti agar tidak terlalu sering begadang setiap malam. Seperti bunyi lirikliriknya, "Begadang jangan begadang/ Kalau tiada artinyal Begadang boleh saja, asal ada perlunya/...".

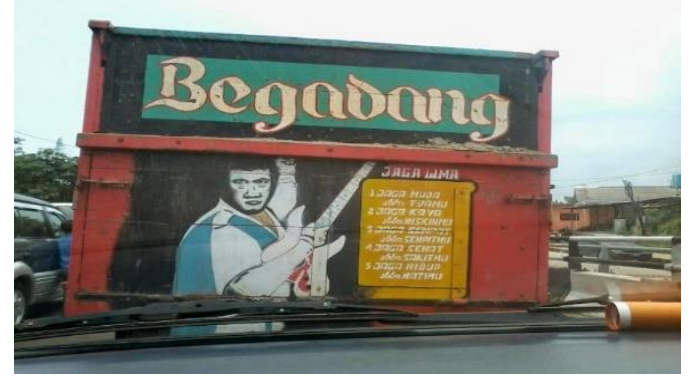

Gambar 19 Grafiti Bak Truk Genre Judul Lagu "Begadang" 
Lain judul lagu "Begadang", lain pula judul lagu "Asal Kau Bahagia" (Gambar 20). Lagu "Asal Kau Bahagia" karya Armada tentang kisah seseorang yang merelakan kekasih hatinya pergi dengan orang lain asalkan bahagia. Seperti liriklirik lagunya, "Katakanlah sekarang bahwa kau tak bahagial Aku punya ragamu tapi tidak hatimul Kau tak perlu berbohong kau masih menginginkannyal Kurela kau dengannya asal kan kau bahagia." Lewat grafiti itu, si sopir ingin menyampaikan pesan bahwa dirinya akan bahagia bilamana kekasihnya juga berbahagia dengan orang lain.

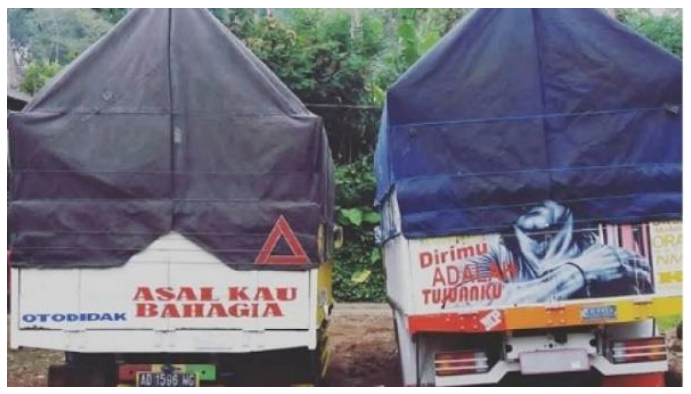

Gambar 20 Grafiti Bak Truk Genre Judul Lagu "Asal Kau Bahagia"

\section{SIMPULAN}

Berdasarkan uraian hasil dan pembahasan di atas, diperoleh kesimpulan sebagai berikut. Pertama, wujud grafiti bak truk terdiri atas tiga jenis, yaitu wacana grafiti bak truk dalam bahasa Indonesia, bahasa daerah (Jawa), dan bahasa asing (Inggris). Kedua, tujuan wacana grafiti bak truk terdiri atas empat jenis, yaitu fungsi ekspresif, fungsi fatis, fungsi kognitif, dan fungsi komunikatif. Ketiga, genre wacana grafiti bak truk terdiri atas empat jenis, yaitu genre doa, genre pantun kilat, genre idiom, dan genre judul lagu.

\section{DAFTAR PUSTAKA}

Badan Pengembangan dan Pembinaan Bahasa. (2016). Kamus Besar Bahasa Indonesia. Retrieved from https://kbbi.kemdikbud.go.id/

Hoogervorst, T. G. (2009). Urban dynamics An impression of Surabaya's sociolinguistic setting. Wacana, 11(1), 39-56.

Ismail, H. S. (2016). Analisis tindak tutur Basa Jawi ing wacana graffiti truk. Bening: Jurnal Penelitian Mahasiswa Prodi Pendidikan Bahasa Jawa, 1(3), 25-34.

Junawaroh, S. (2015). Analisis tindak tutur Basa Jawi ing wacana graffiti truk. Humanika, 21(1), 49-55.

Kridalaksana, H. (2011). Kamus linguistik edisi keempat. Jakarta: Gramedia Pustaka Utama.

Krippendorf, K. (2004). Content analysis: An introduction to its methodology. London: Sage.

Meliana, I. (2014). Reader's interpretation on social criticism toward Soeharto found in truck graffiti. Jurnal Ilmiah Mahasiswa FIB, 3(10), 1-4.

Sudaryanto. (2017). Kamus umum bahasa dan ilmu bahasa. Yogyakarta: Samudra Biru.

Wicandra, O. B. (2009). Representasi perempuan pada lukisan di bak truk. Nirmana, 9(1), 31-37. 